\title{
The Ceiling Jet in Fires
}

\author{
HOWARD W. EMMONS \\ Division of Applied Sciences \\ Harvard University \\ Cambridge, Massachusetts 02138, USA
}

\section{ABSTRACT}

The steady fire-produced ceiling jet in an open ended corridor is examined with a simplified "top hat" theory. At a corridor open end, the hot fluid accelerates upward producing a Richardson Number equal to 1 for tranquil flow as the flow control. Friction satisfies this condition by upstream waves with a hydraulic jump, if necessary. Entrainment has qualitatively the same result, but with quantitative differences. Heat transfer at low friction causes the Richardson Number and depth to rise. The manner of adjustment to $\mathrm{Ri}=1$ at an open end needs further study.

\section{INTRODUCTION}

The hot gases from a fire rise to the ceiling and spread out radially. This process has been variously studied both by boundary layer type theories and experiment. $[1,2]$ The layer cools and becomes deeper as its radius increases. The heat transfer has been of major concern. $[3,4]$ In a few cases, the ceiling jet in a corridor--a simpler geometry--has been studied. A full three-dimensional theory $[5,6]$ shows the expected bulbous front of the transient jet which is well known from hydraulic experiments $[7,8]$ but which is of little importance in fire spread.

The simplest theory, with the assumption of uniform temperature and velocity with depth, does not seem to have been exploited and is used here to find, if possible, a simple treatment suitable for fire modeling. The case of an open ended corridor is studied.

\section{GENERALEQUATIONS}

By reference to Figure 1, the following basic equations are obtained.

\section{Conservation of Mass}

$\frac{\mathrm{d} \dot{\mathrm{n}}}{\mathrm{dx}}=\mathrm{Epu}$

Conservation of Momentum

$$
\frac{\mathrm{d} i n u}{\mathrm{dx}}=-\mathrm{g}^{\prime} \rho \delta \frac{\mathrm{d} \delta}{\mathrm{dx}}+\frac{g \delta^{2}}{2} \frac{\mathrm{d} \rho}{\mathrm{dx}}-\frac{f}{2} \rho u^{2}
$$

Conservation of Energy

$$
\frac{\operatorname{dinc}_{p}\left(T-T_{a}\right)}{d x}=-h\left(T-T_{a}\right)
$$




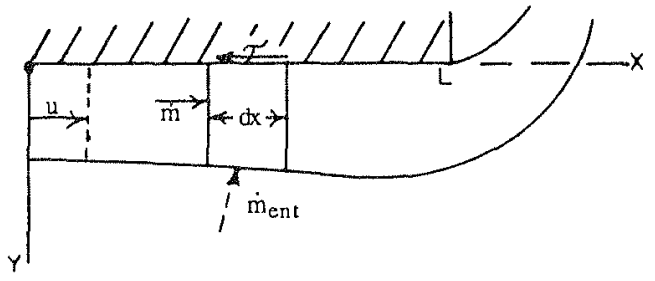

FIGURE 1. "Top Hat" velocity and temperature profile ceiling jet in an open-ended corridor.

\section{THE BASIC FLOW}

Consider first a hot perfect fluid ceiling jet with no friction, no entrainment, and no heat transfer. The basic equations then become

$$
\text { (1- Ri) } \frac{\mathrm{d} \delta}{\mathrm{dx}}=0
$$

Equation (4) indicates that the jet depth cannot change unless the Richardson Number equals 1 , i.e., the stream velocity equals the shallow water surface wave speed

$$
u=\sqrt{g^{\prime} \delta}
$$

With the jet moving at this speed, upstream waves remain stationary, while downstream waves wash out.

\section{THE EFFECT OF CEILING FRICTION}

With no entrainment and no heat transfer, the mass flow, $\dot{m}$, and density $\rho$, are constant and the basic equations reduce to

$$
(1-\mathrm{Ri}) \frac{\mathrm{d} \delta}{\mathrm{dx}}=\frac{\mathrm{f}}{2}
$$

Thus, if

$$
\operatorname{Ri}\left\{\begin{array}{l}
>1 \\
=1 \\
<1
\end{array}\right.
$$

$$
\text { then } \frac{\mathrm{d} \delta}{\mathrm{dx}}\left\{\begin{array}{cc}
<0 & \text { tranquil flow } \\
=\infty & \text { critical flow } \\
>0 & \text { shooting flow }
\end{array}\right.
$$

A tranquil flow is deeper than and decreases to critical while a shooting flow is less deep than and increases to critical. By $R i=1$, the critical depth is

$\delta_{c}=\left(\frac{\dot{\mathrm{m}}^{2}}{\mathrm{~g}^{\prime} \mathrm{p}^{2}}\right)^{1 / 3} \quad$ and $\quad \mathrm{Ri}=\left(\frac{\delta}{\delta_{c}}\right)^{3}$

Equation (6) with the origin at the position of critical flow (see Figure 2) integrates to $\frac{\delta}{\delta_{c}}-\frac{1}{4}\left(\frac{\delta}{\delta_{c}}\right)^{4}-\frac{3}{4}=\frac{f x}{2 \delta_{c}}$ 


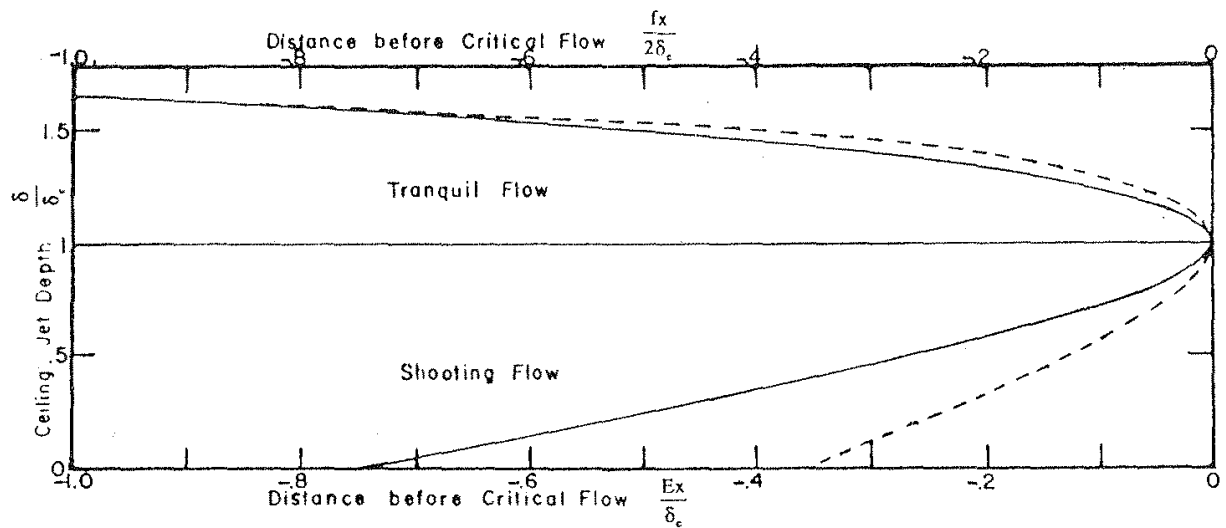

FIGURE 2. Effect of friction and entrainment on a ceiling jet flow: - friction - top scale;

entrainment - bottom scale

If the comidor ends before critical flow is reached, a tranquil flow will accelerate and waves travel upstrean to the source to reach a steady flow. If the jet has $\mathrm{Ri}<1$, the flow will merely shoot out since no adjusting waves can move upstream.

On the other hand, if critical flow is reached before the end of the corridor, all remaining momentum is needed to produce the very rapid depth increase and none is available to resist the friction. The leading edge flow is stopped. If the flow is tranquil, waves slow the motion, the friction force decreases and the critical flow moves to the corridor end. If the flow is shooting, the blocked flow produces a hydraulic jump which moves upstream until critical flow is reached at the end. The jet discussion so far is identical to that for hydraulic channel flow. [9]

\section{THE EFFECT OF ENTRAINMENT}

With no friction and no heat transfer, one might suppose that entrainment would merely add some additional mass to the ceiling jet flow. However, entrainment not only adds mass, but also, because the new mass must be accelerated, applies a drag on the ceiling jet and, because the new mass must be heated from the ambient to jet temperatu re, cools the ceiling jet, and increases its density. Entrainment by itself has all the effects of the entire problem. This full problem is discussed in a later section.

Because strong buoyancy lends to suppress instabilities, entrainment is often very small.[10,11] The entrainment cocfficient measured by Atallah [10] is only $\mathrm{E}=.003$. This section will calculate the effect of small entrainment for which the temperature change is negligible. The basic equations then become.

$(1-\mathrm{Ri}) \frac{\mathrm{d} \delta}{\mathrm{dx}}=2 \mathrm{E}$

Thus, the acceleration of the entrained fluid puts a drag on the ceiling jet with the same effect as that of friction, equation (7).

Equation (10) cannot be directly integrated because Ri varies with both $\delta$ and $\dot{m}$. However, the momentum equation can be integrated directly, then by elimination of u we get $\frac{3}{2}\left(\frac{\delta}{\delta_{c}}-\frac{1}{\sqrt{3}} \ln \frac{\sqrt{3}+\delta / \delta_{c}}{\sqrt{3}-\delta / \delta_{c}}\right)-.3595=\frac{E x}{\delta_{c}}$

where, again, $x=0$ at $\mathrm{Ri}=1$.

The critical flow depth $\delta_{\mathrm{c}}$ is given by

$\frac{\delta_{0}}{\delta_{c}}=\left\{\frac{1}{3}\left(2 \mathrm{Fr}^{2}-1\right)\right\}^{1 / 2}$

The effect of entrainment is again shown in Figure 2, with a change of corridor length scale. The required flow adjustments to reach $\mathrm{Ri}=1$ at the end for various corridor lengths are identical to those for friction. 


\section{THE EFFECT OF HEAT TRANSFER}

With friction and entrainment absent, the basic equations reduce to

$(1-\mathrm{Ri}) \frac{\mathrm{d} \delta}{\mathrm{dx}}=\delta\left(1+\frac{\mathrm{T}_{\mathrm{a}}}{2\left(\mathrm{~T}-\mathrm{T}_{\mathrm{a}}\right)}\right) \frac{1}{\mathrm{~T}} \frac{\mathrm{dT}}{\mathrm{dx}}$

on using the gas law to replace $\rho$ with $\mathrm{T}$.

We note that for a fire ceiling jet, which cools as it flows, the right side of equation (13) is negative so that

if $\quad \operatorname{Ri}\left\{\begin{array}{l}>1 \\ =1 \\ <1\end{array} \quad\right.$ then $\frac{\mathrm{d} \delta}{\mathrm{dx}}\left\{\begin{array}{ccc}>0 & \text { tranquil flow } \\ =\infty & \text { critical flow } \\ <0 & \text { shooting flow }\end{array}\right.$

By comparing equation (14) with equation (7), we see that the effect of heat transfer is opposite to that of friction and entrainment.

Since $\mathrm{Ri}$ is dependent upon both $\mathrm{T}$ and $\delta$, Equation (13) cannot be integrated analytically. However, using Ri as variable, we get

$\frac{1-R i}{R i(2+R i)} \frac{d R i}{d T}=\frac{1}{2} \frac{2 T-T_{a}}{T\left(T-T_{a}\right)}$

With the boundary condition that at $\mathrm{x}=0 ; \mathrm{Ri}=\mathrm{Ri}$ and $\mathrm{T}=\mathrm{T}_{0}$, this integrates to

$\frac{\mathrm{Ri}}{(2+\mathrm{Ri})^{3}}=\frac{\mathrm{Ri}_{0}}{\left(2+\mathrm{Ri}_{0}\right)^{3}} \frac{\mathrm{T}-\mathrm{T}_{\mathrm{a}}}{\mathrm{T}_{0}-\mathrm{T}_{\mathrm{a}}}\left(\frac{\mathrm{T}}{\mathrm{T}_{0}}\right)$

The critical condition appears as the maximum of the left-hand side. Using the energy equation in the integrated form

$\mathrm{T}-\mathrm{T}_{a}=\left(\mathrm{T}_{0}-\mathrm{T}_{\infty}\right) \mathrm{e}^{-\zeta}$

where $\zeta=\mathrm{hx} / \mathbf{m c}_{\mathrm{p}}$. The Richardson Number -- position relation becomes

\section{TABLE 1}

\begin{tabular}{l|c|c} 
& $\mathrm{I}$ & $\mathrm{Il}$ \\
\hline Ambient temperature & 300 & 294 \\
Initial temperature & 800 & 384.3 \\
Mass flux & .16667 & .025 \\
Heat transfer coefficient & 41.65 & 10.6 \\
Initial Richardson Number & various & 1.195 \\
linc $_{p}$ & .24694 & .41897 \\
Distance along conidor x meters & $4.0496 \zeta$ & $2.3868 \zeta$ \\
\hline
\end{tabular}

$\frac{\mathrm{Ri}}{(2+\mathrm{Ri})^{3}}=\frac{\mathrm{Ri}_{0}}{\left(2+\mathrm{Ri}_{0}\right)^{3}}\left\{\frac{\mathrm{T}_{\mathrm{a}}}{\mathrm{T}_{0}}+\left(1-\frac{\mathrm{T}_{\mathrm{a}}}{\mathrm{T}_{0}}\right) \mathrm{e}^{-\zeta}\right\} \mathrm{e}^{-\xi}=\frac{\mathrm{Ri}_{0}}{\left(2+\mathrm{Ri}_{0}\right)^{3}} \frac{\mathrm{T}}{\mathrm{T}_{0}} \mathrm{e}^{-\zeta}$

Since this equation contains $\mathrm{Ri}_{0}$ and $\mathrm{T}_{\mathrm{a}} / \mathrm{T}_{0}$ as parameters, we present the solution to equation (18) using the case in Column 1, Table 1, and is shown in Figures 3 and 4 . For tranquil flow, both $\mathrm{Ri}$ and $\delta$ increase indefinitely while, for shooting flow, Ri goes to zero (because $\rho \rightarrow$ $p_{a}$ ) while $\delta$ becomes asymptotic to some finite value. To appreciate how rapid these thermal effects really are, the physical distance along the corridor is for the present case

$\mathrm{x}=\frac{\dot{\mathrm{m}} \mathrm{c}_{\mathrm{p}}}{\mathrm{h}} \zeta=4.050 \zeta$ 
Thus, $\zeta=5$ corresponds to only $x=20.25$ meters. The above computation was made with equation (18) using

$y^{3}=\left(\frac{\delta}{\delta_{0}}\right)^{3}=\frac{R i}{\mathrm{Ri}_{0}}\left(\frac{\mathrm{T}}{\mathrm{T}_{0}}\right)^{2} \mathrm{e}^{\zeta}$

to compute the ceiling jet depth.

If the depth is to be computed directly, $\mathrm{Ri}$ can be eliminated between equations (18) and $(20)$ to get the cubic equation for $y$

$\operatorname{Ri}_{0}\left(\frac{T_{0}}{T}\right)^{2} e^{-\zeta} y^{3}-\left(2+R i_{0}\right) \frac{T_{0}}{T} y+2=0$

We note that critical flow does not appear at the corridor end. This will be further discussed in the concluding section.

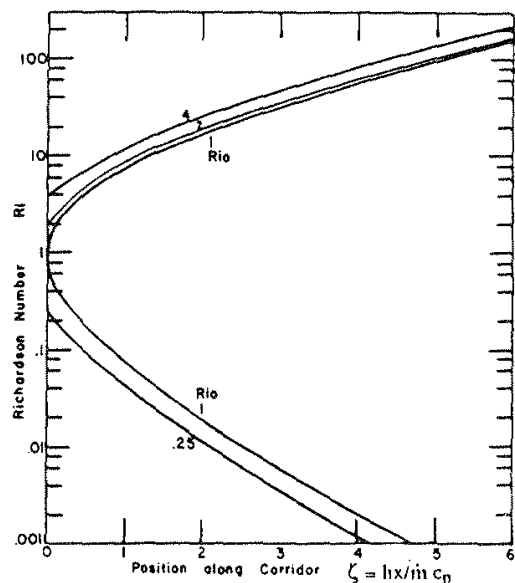

FIGURE 3. Effect of heat transfer and initial

Richardson Number on a ceiling jet

Richardson Number (Case column 1, Table 1)

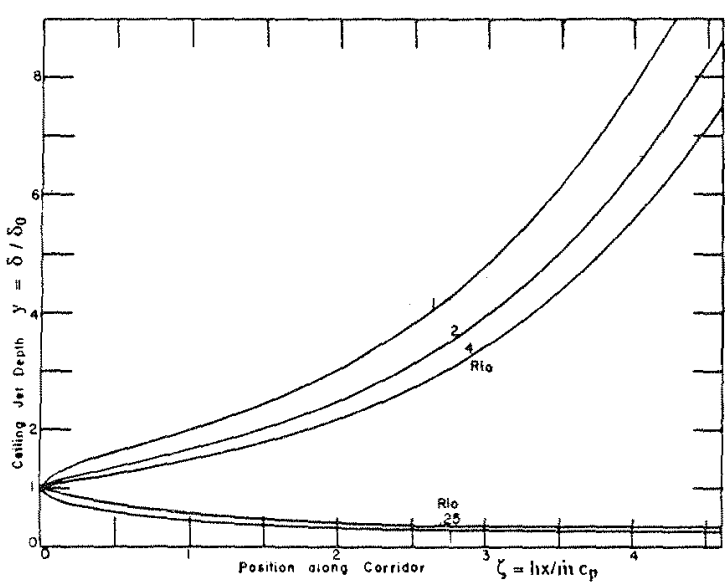

FIGURE 4. Effect of heat transfer and initial Richardson Number on a ceiling jet depth. (Case column 1, Table 1)

GENERAL CEILING JET WITH FRICTION, ENTRAINMENT, AND HEAT TRANSFER

The general equations have not been solved analytically, but, following the methods of the last section, the results can be put into several useful forms.

$\frac{1-\mathrm{Ri}}{\mathrm{Ri}(2+\mathrm{Ri})} \frac{\mathrm{dRi}}{\mathrm{d} \zeta}=\frac{1}{2} \frac{2 \mathrm{~T}-\mathrm{T}_{\mathrm{a}}}{\mathrm{T}\left(\mathrm{T}-\mathrm{T}_{\mathrm{a}}\right)} \frac{\mathrm{dT}}{\mathrm{d} \zeta}+\frac{3 \mathrm{f}}{2 \mathrm{Hy}(2+\mathrm{Ri})}+\frac{2 \mathrm{E}}{\mathrm{Hy}}$

Again, the first two terms can be integrated while the last two remain to be numerically evaluated.

$\frac{\mathrm{Ri}}{(2+\mathrm{Ri})^{3}}=\frac{\mathrm{Ri}_{0}}{\left(2+\mathrm{Ri}_{0}\right)^{3}} \frac{\mathrm{T}-\mathrm{T}_{\mathrm{a}}}{\mathrm{T}_{0}-\mathrm{T}_{\mathrm{a}}} \frac{\mathrm{T}}{\mathrm{T}_{0}} \mathrm{e}^{3 \frac{\mathrm{f}}{11} \int_{0}^{5} \frac{\mathrm{d}}{\mathrm{y}(2+\mathrm{Ri})}} \mathrm{e}^{4 \frac{\mathrm{E}}{11} \int_{0}^{5 \mathrm{~d} \zeta} \frac{\mathrm{y}}{\mathrm{y}}}$

Because of entrainment, the mass flow and energy equations become

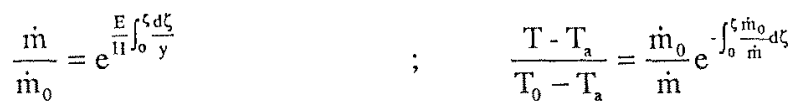

which reduces to equation (17), if there is no entrainment. Thus, equation (23) takes the final form 


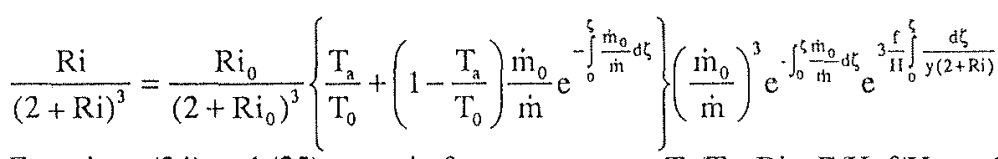

Equations (24) and (25), contain four parameters, $\mathrm{T}_{\mathrm{a}} / \mathrm{T}_{\mathrm{O}}, \mathrm{Ri} \mathrm{i}_{\mathrm{O}}, \mathrm{E} / \mathrm{H}, \mathrm{f} / \mathrm{H}$, and has not yet been fully explored. However, we see by equation (22) that, since the temperature decreases, the first term on the right is negative while the friction and entrainment terms are plus, thus counteracting the effect of heat transfer.

THE EFFECT OF FRICTION AND HEAT TRANSFER

We now consider, in some detail, the simpler case with $E=0$.

$\frac{R i}{(2+R i)^{3}}=\frac{R i_{0}}{\left(2+R i_{0}\right)^{3}}\left\{\frac{T_{a}}{T_{0}}+\left(1-\frac{T_{a}}{T_{0}}\right) e^{-\zeta}\right\} e^{-\zeta} e^{3 \frac{1}{1 i} \int_{0}^{\frac{d}{y(2+R i)}}}$

The solution is shown in Figures 5 and 6 for the case of Column I, Table 1, for tranquil flow for $\mathrm{Ri}_{0}=2$. Ignoring, for the moment, the line to point 0 , all solutions for various values of $f$, loop down to $R i=1$ for large $f$ or swoop up to infinity for small $f$. With more decimal places to $f$ the curves move towatd higher $\zeta$.

To understand this behavior, the differential equation (22), eliminating $\mathrm{dT} / \mathrm{d} \zeta$ by equation (3), is put into the form

$\frac{d R i}{d \zeta}=\frac{R i}{2 y}\left\{\frac{\frac{3 f}{H}-(2+R i)\left(2-\frac{T}{T}\right) y}{1-R i}\right\}$

Then, eliminating y from the numerator, using equation (20) we get

$\frac{d R i}{d \zeta}=\frac{R i}{2 y}\left(\left(\frac{T}{T_{0}}\right)^{2} e^{-\zeta \zeta}\right)^{1 / 3}\left(2-\frac{T_{a}}{T}\right) \frac{f}{H}\left\{\frac{3\left(\left(\frac{T_{0}}{T}\right)^{2} e^{-\zeta}\right)^{1 / 3}\left(2-\frac{T_{a}}{T}\right)^{-1}-\frac{\operatorname{HRi}^{1 / 3}(2+R i)}{f i_{0}^{1 / 3}}}{1-R i}\right\}$

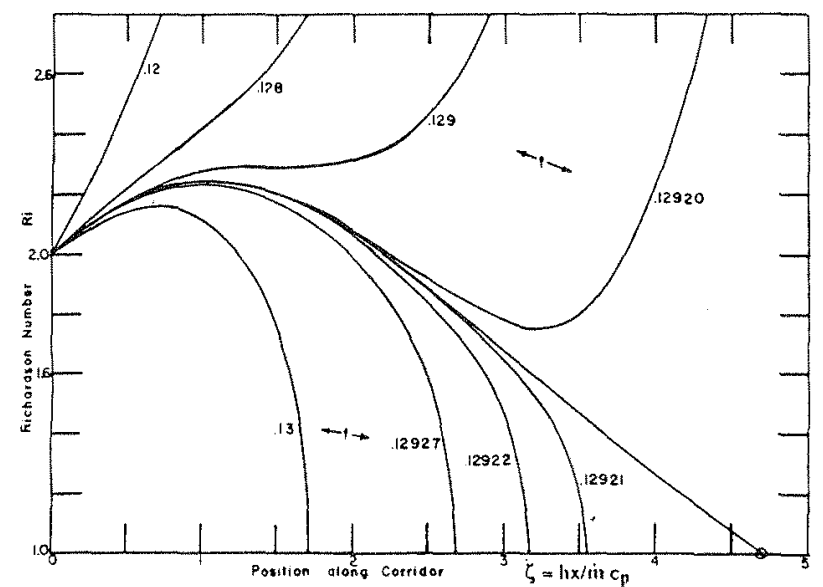

FIGURE 5. Effect of heat transfer and friction on the Richardson Number of a ceiling jet. Initial Richardson Number $=2$. (Case column 1 , Table 1$)$ 


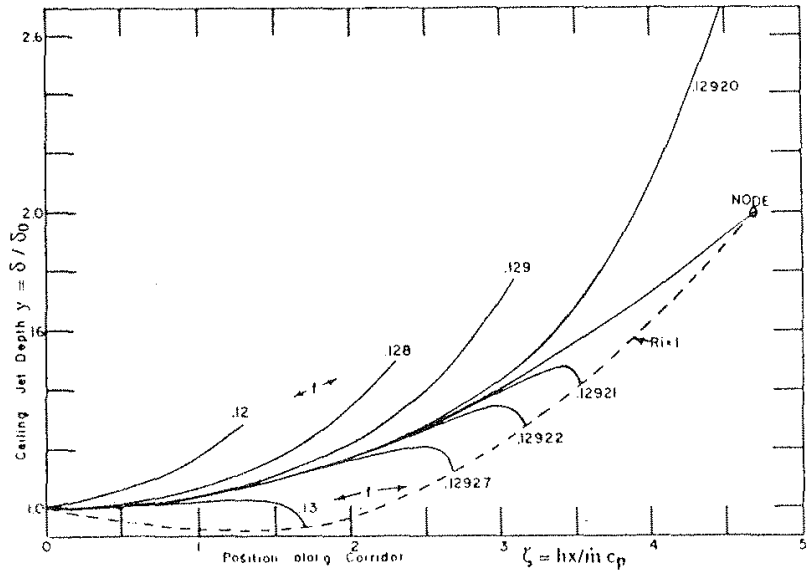

FIGURE 6. Effect of heat transfer and friction on a ceiling jet depth. Initial Richardson Number $=2$. (Case column 1, Table 1).

From this we see that

$\frac{\mathrm{dRi}}{\mathrm{d} \zeta}=\infty \quad$ at $\mathrm{Ri}=1 \quad$ and $\quad \frac{\mathrm{dRi}}{\mathrm{d} \zeta}=0$ at $\mathrm{r}=\varphi(\zeta)$

where

$\mathrm{I}=\frac{\mathrm{HRi}^{1 / 3}(2+\mathrm{Ri})}{\mathrm{fRi}_{0}^{1 / 3}} ; \varphi(\zeta)=3\left(\left(\frac{\mathrm{T}_{0}}{\mathrm{~T}}\right)^{2} \mathrm{e}^{-\zeta}\right)^{1 / 3}\left(2-\frac{\mathrm{T}_{\mathrm{a}}}{\mathrm{T}}\right)^{-1} ; \frac{\mathrm{T}}{\mathrm{T}_{\mathrm{a}}}=1+\left(\frac{\mathrm{T}_{0}}{\mathrm{~T}_{\mathrm{a}}}-1\right) \mathrm{e}^{-\zeta}$

Figure 7 shows the solutions of Figures 5 and 6 as $r$ vs. $\zeta$ with the additional line on which $\mathrm{d} t / \mathrm{d} \zeta=0$ which depends only upon the thermal properties of the flow.

The point 0 at $\zeta=4.683$ in Figure 7 is a node. Since the coefficient of the bracket in equation (28) is positive, while both the numerator and denominator are positive below and negative above their respective lines, the solution slopes are as indicated and the node is a saddle point.

The slopes of the solution curves passing through the node are found by evaluation of equation (27) as a $0 / 0$ form. After considerable algebra we find

$\left.\frac{\mathrm{dRi}}{\mathrm{d} \zeta}\right|_{n}=1-(1 \pm \sqrt{3}) \frac{\mathrm{T}_{\mathrm{a}}}{2 \mathrm{~T}_{\mathrm{n}}}$

where $\mathrm{T}_{\mathrm{n}}$ is the jet temperature at the node position. The corresponding slopes shown

$\because \mathscr{O}^{-\infty}$ in Figure 7 are

$\left.\frac{\mathrm{dr}}{\mathrm{d} \zeta}\right|_{n}=\frac{2}{3} \mathrm{r}_{\mathrm{n}}\left(1-(1 \pm \sqrt{3}) \frac{\mathrm{T}_{\mathrm{a}}}{2 \mathrm{~T}_{\mathrm{n}}}\right)$

The solution curves through the node in Figures 5,6, and 7 were obtained by starting at the node with $f=.12920$ and the negative slope given by equation (32) integrating toward $\zeta=0$, using equation (23) in the form $(\mathrm{E}=0)$

$\frac{\mathrm{Ri}}{(2+\mathrm{Ri})^{3}}=\frac{\left\{1+\left(\mathrm{T}_{0} / \mathrm{T}_{\mathrm{a}}-1\right) \mathrm{e}^{-\zeta}\right\} \mathrm{e}^{-\zeta}}{27\left\{1+\left(\mathrm{T}_{0} / \mathrm{T}_{\mathrm{a}}-1\right) \mathrm{e}^{-\zeta \mathrm{a}}\right\} \mathrm{e}^{-\zeta a}} \mathrm{e}^{3 \frac{f}{11} \int_{\zeta a}^{\zeta} \frac{d \zeta}{y(2+R i)}}$ 


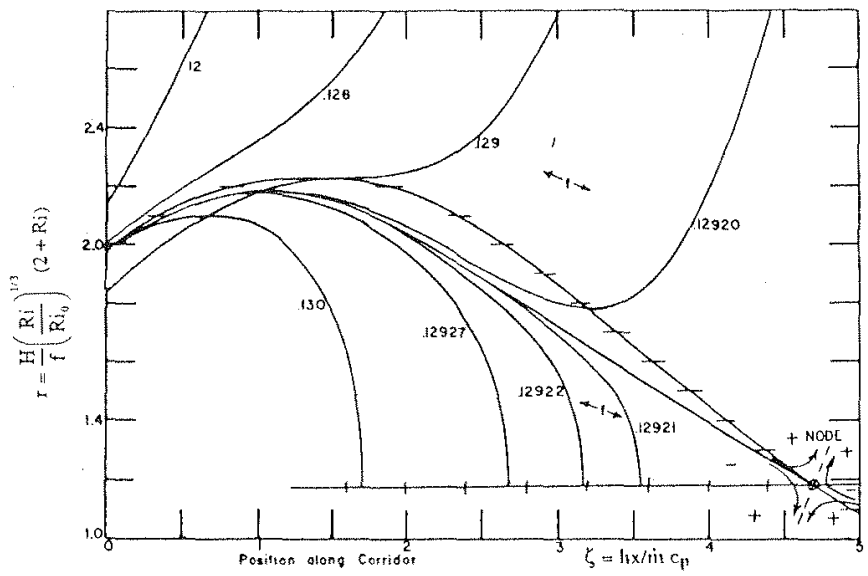

FIGURE 7. Effect of heat transfer and friction on a ceiling jet flow. Initial Richardson Number $=2$. (Case column 1, Table 1). line on which solutions have horizontal slope; - + \& line, $\mathrm{Ri}=1$, on which solutions have vertical slope; + , show sign of slope in region between above lines.

\section{THE CEILING JET}

In this section, we apply the above theory to an arbitrary fire-produced ceiling jet, in tranquil flow, in an open ended corridor of arbitrary length. Such a case is defined by the parameters $m, T_{0}, T_{a}, h, f, L, R_{0}$. We note immediately that $R_{0} i_{0}$ may be altered by the $\mathrm{R} i=1$ control at the open end.

$\zeta_{e}=\frac{h \mathrm{~L}}{\min c_{p}}$.

From this, we find the sign of the numerator in brackets of equation (27) in the form

$$
N=\frac{f}{h / \dot{m} c_{p}}-\left(2-\frac{T_{a}}{T_{e}}\right) \delta_{e} \quad \text { and } \quad \delta_{c}=\left\{\frac{\dot{m}^{2}}{\rho_{e}^{2} g_{e}^{\prime}}\right\}^{1 / 3}
$$

where $\mathrm{Ri}=1$, and $\delta_{0}$ has been canceled out. For $\mathrm{Ri}>1$ in the corridor, $\mathrm{d} \mathrm{Ri} / \mathrm{d} \zeta$ is opposite in sign to $\mathrm{N}$. If $\mathrm{N}>0$, the corridor ends before the node is reached.

Thus, the solution to equation (33), starting at $\mathrm{Ri}=1$ at the end, will have a negative slope and $\mathrm{Ri}$ will increase back to $\zeta=0$, to the required value of $\mathrm{Ri}_{0}$. The velocity and depth of the fluid source will be altered appropriately. ${ }^{*}$ If $N=0$, the corridor end is at the node and the backward solution to equation (33) starting at $\zeta=\zeta_{\mathrm{n}}$ must start with the negative slope given by equation (31). Again, $\mathrm{Ri}_{0}$ will come from the solution and requires source adjustment. ${ }^{*}$ If $\mathrm{N}<0$, the corridor ends after the node and the solution slope for $\mathrm{Ri}>1$ is positive, the solution starting at the end moves toward $\zeta>\zeta_{\mathrm{e}}$ and no solution with the given data exists for $\zeta<\zeta_{\mathrm{e}}$ with $\mathrm{Ri}=1$ at the end. See the concluding section for further comments on this case.

\section{COMPARISON WITH EXPERIMENT}

Although there are many papers on ceiling jet measurements, [12-14] few are detailed enough to guide the theory. A recent $\mathrm{Ph} . \mathrm{D}$. thesis [15] provides both careful measurements over a narrow range of conditions and a careful boundary layer theory with appropriate velocity and temperature profiles. This theory failed completely to fit the data and was abandoned in favor of the completely unfounded assumption that $\mathrm{Ri}=1$ everywhere. This assumption agreed fairly well with the data (see Figures 8 and 9).

\footnotetext{
* "Source adjustment" does not mean any effect on the fire. It means change of depth and velocity after the fire plume reaches the ceiling.
} 

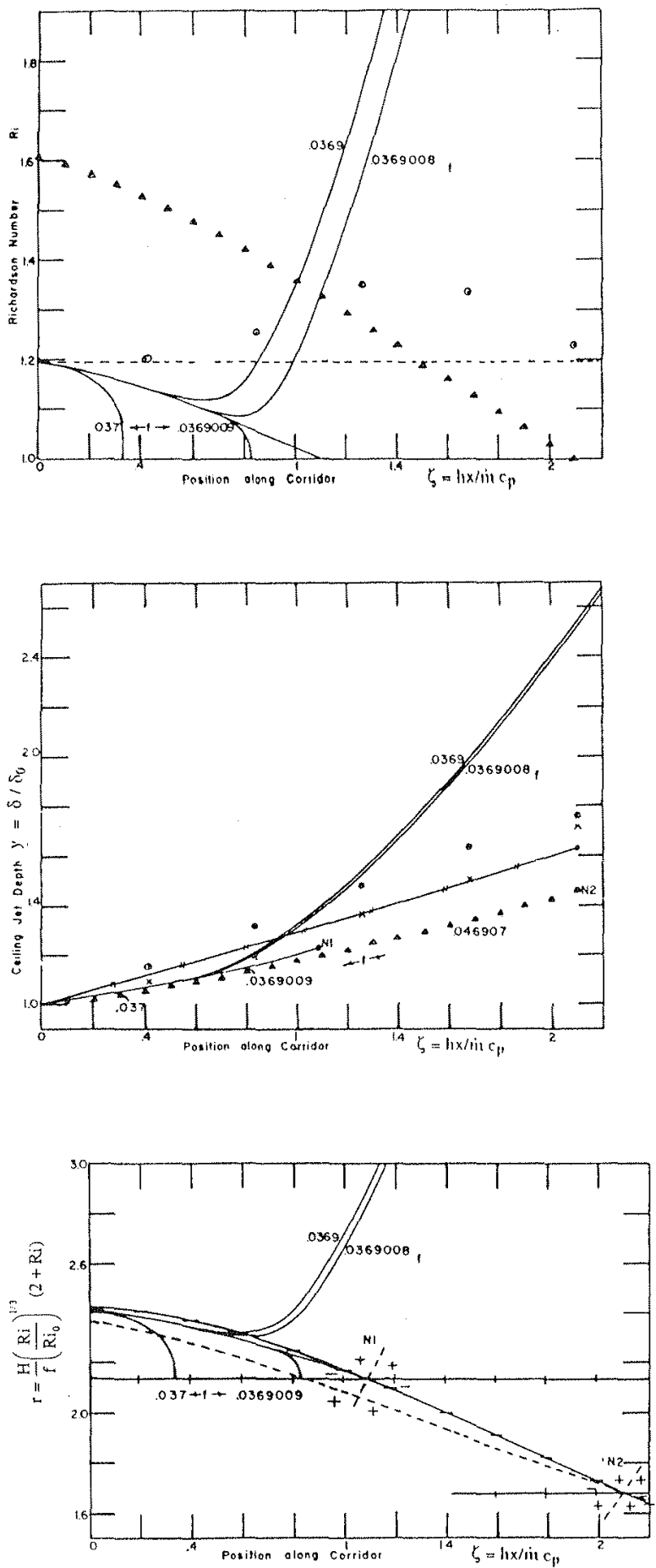

TMGURE 8. Richardson Number for Chobotov (15) experiment. (A) Experimental result; Present theory with data column 2, Table 1 and various friction factors;

$\triangle$ Present theory with node at end of experimental channel; .... Arbitrary assumption $\mathrm{Ri}=\mathrm{Ri} 0$ which gives "best fit" to data.

Figure 9. Ceiling jet depth for Chobotov (15) experiment. $\odot$ Experimental result; Present theory witl data column 2, Table 1 , and various friction factors; $\triangle$ Present theory with node at end of experimental channel; $x$ Arbitrary assumption $\mathrm{Ri}=\mathrm{RiO}$ which gives "best fit" to data; - H- Chobotov (15) boundary layer theory with arbitrary assumption $R \mathrm{i}=1$.

EIGURE 10. Elfect of heat transfer and friction on the ceiling jet in the Chobotov (15) experiment. Present

theory with data column 2 , Table 1 , and various friction factors;

$\rightarrow$ Line on which solutions have horizontal slope; + Lines, $\mathrm{Ri}=1$ different $\mathrm{f}$, on which solutions have vertical slope; + , show sign of slope in region between above lines; N1 - Node implied by experimental initial data; N2 - Node moved to the end of the experimental channel ; ... Solution from node at end. 
The top hat theory developed in this paper was applied to the Chobotov experiment computed with the data of Column II, Table 1. The results are shown in Figures 8-10. Computation from $\zeta=0$ contains a node far short of the end which shows why the boundary layer [15] attempt at solution failed.

If the node of the top hat theory is moved to the end of the experiment (by selecting a higher friction coefficient), ${ }^{+}$the resulting prediction is shown in Figures 8-10. The agreement with the ceiling jet depth is only fair while the agreement with the measured Richardson Number is very poor. throughout.

Better agreement is obtained with the completely unfounded assumption that $\mathrm{Ri}=\mathrm{Ri}$

\section{CONCLUSIONS}

The simple top-hat type theory used in this paper would be expected to yield a correct qualitative semi-quantitative solution to the flow of buoy ant fire gases along a ceiling. So long as the corridor is not too long, the heat transfer not too large, or the friction and entrainment not too small, reasonable-looking results are obtained satisfying the open end outlet condition for tranquil flow of Richardson Number $=$ Froude Number $=1$.

However, for many cases, there appears to be no solution satisfying $\mathrm{Ri}=1$ at the end. The reason for this is not clear. If the ceiling jet arrives at the open end with $\mathrm{Ri}>1$, the jet is too deep and the fluid "falls out" with acceleration. Thus, the adjustment could take place beyond the end of the corridor.

If this were the case, the increased velocity and decreased depth would be expected to

propagate upstream at the wave speed $\sqrt{g^{\prime} \delta}$ which is higher than the end fluid velocity. The correct explanation would appear to be either non top-hat adjustments at and just outside of the end of the corridor, or some non-steady effects with localized fluid accumulation and discharge suggested by observations of persons fleeing from a fire who state that "the fire came rolling along the ceiling."

Another phenomena sometimes intervenes to alter the $\mathrm{Ri}=1$ problem. As the ceiling jet moves along the corridor and cools off, its buoyancy falls and it is more easily removed from the ceiling by drafts or other disturbances. In the case of fire, there is often a lower layer current of atmospheric air returning into the fire source. This lower level return current can entrain the extra deep, extra cool ceiling jet which, therefore, never reaches the corridor end.

It is clear that some scientifically motivated ceiling jet studies are essential to guide further theoretical work on the ceiling jet.

The theory of this paper is about the right complexity for use in a general fire model, with some empirical coefficients, if necessary. It needs to be further developed to include partially open or closed corridors. It needs to be extended to the two dimensional ceiling of a room and needs to include residual fuel which is burning.

\section{NOMENCLATURE}

$$
\begin{aligned}
& c_{p} \\
& \mathrm{E} \\
& \mathrm{g}
\end{aligned}
$$

$$
\begin{aligned}
& \mathrm{g}^{\prime}=\mathrm{g} \frac{\rho_{\mathrm{a}}-\rho}{\rho} \\
& \mathrm{h} \\
& \mathrm{H}=\mathrm{h} \delta_{0} / \dot{\mathrm{m}} \mathrm{c}_{\mathrm{p}} \\
& \dot{\mathrm{m}}
\end{aligned}
$$

specific heat of ceiling jet gas at constant pressure entrainment coefficient, Equation (1) friction factor, Equation (2) acceleration of gravity

effective acceleration of gravity, Equation (5) heat transfer coefficient, Equation (3) heat transfer factor, Equation (22) ceiling jet mass flow per unit width, Equation (1)

\footnotetext{
+ The experimental measurements suggested a very low friction. Thus, the friction factor of $\mathrm{f}=.046907 \mathrm{required}$ to put the node at the end seems unreasonably large.
} 
numerator of $\left.\frac{\mathrm{dRi}}{\mathrm{d} \zeta}\right|^{\mathrm{n}}, \quad$ Equation (35)

$r=\frac{H(R i)^{1 / 3}(2+R i)}{f\left(R i_{0}\right)^{1 / 3}}$
$R i=g^{\prime} \delta / u^{2}$

$\mathrm{Ri}_{0}$ useful analysis variable, Equation (30)

Richardson Number, Equation (4)

Richardson Number at jet source, Equation (16)

temperature

ceiling jet velocity

distance along corridor [m]

ceiling jet depth, Equation (20)

ceiling jet depth [m]

curve on which $\mathrm{dr} / \mathrm{d} \zeta=0$, Equation (30)

ceiling jet density

coordinate along conidor

\section{SUBSCRIPTS}

$a$
c
e
ENT
$n$
0

ambient

critical $(\mathrm{Ri}=1)$

open end of corridor

entrained

node

source of ceiling jet

\section{REFERENCES}

1. Alpert, R., "Turbulent Ceiling Jet Induced by Large Scale Fires," Comb. Sci. and Tech. 11, 197-213, 1975.

2. You, H. Z. and Faeth, G. M., "Ceiling Heat Transfer During Plume Impingement," Fire and Materials, 3(3), 140-147, 1979.

3. Zukoski, E.E. and Kubota, T., Experimental Study of Environment and Heat. Transfer in a Room Fire, NIST-GCR-88-554, 1988.

4. Cooper, L.Y. and Stroop, D.W., "Thermal Response of Unconfined Ceilings Above Growing Fires and the Importance of Convective Heat Transfer," Transactions of ASME 109, 172-178, 1987.

5. Baum, H. R., Rehm, R.G., and Mulholland, G.W., "Prediction of Heat and Smoke Movement in Enclosure Fires," Fire Safety Journal, 6(3), 193-201, 1.983.

6. Markatos, N. C., Malin, M. R., and Cox, G., "Mathematical Modeling of Buoyancy Induced Smoke Flow in Enclosures," Int. J. Heat Mass Transfer, 25, 63, 1982.

7. Benjamin, T. B., "Gravity Currents and Related Phenomena," LEFuid Mech., 31, 209-248, 1967. 
8. Simpson, J. E. and Britter, R. E., "The Dynamics of the Head of a Gravity Current Advancing Over a Horizontal Surface," I. Fluid Mechanics, 94(3), 477-495, 1979.

9. Channel Flow Section of any Hydraulics Text; e.g., Rouse H., Fluid Mechanics for Hydraulic Engineers, McGraw Hill, 273-326, 1938.

10. Atallah, S., "Fires in a Model Corridor with a Simulated Combustible Ceiling, Part 1, Fire Research Station," Fire Research Notes, 620, 1966.

11. Ellison, T. H. and Turner, J. S., Turbulent Entrainment in Stratified Flows.

12. Heskestad, G. and Hill, J. P., Experimental Fires in Multiroom/Corridor Enclosures. NBS-GCR-86-502, 1986.

13. Satoh, K. and Miyazaki, S., "A Numerical Study of Large Fires in Tunnels," Rep. Fire Res. Inst of Japin $68,19-34,1989$.

14. Sako, S. and Hasemi, Y., "Response Time of Automatic Sprinklers Below a Confined Cciling," Second Int. Symp. Fire Safety Sci., 613-622, 1989.

15. Chobotov, M. V., "Gravity Currents with Heat Transfer Effects," Ph.D. Thesis, California Institute of Technology, 1987. 